\title{
Um estudo sobre as causas de aumentos de custos e de prazos em obras de edificações públicas municipais
}

\author{
Causes of public projects delays and cost overruns in \\ municipal buildings
}

\section{Henrique de Paula Santos \\ Cícero Murta Diniz Starling \\ Paulo Roberto Pereira Andery}

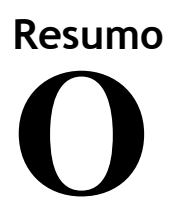

bem como de possíveis diretrizes para a garantia do desempenho dos empreendimentos. O presente trabalho apresenta um estudo diagnóstico sobre o aumento de custos e prazos de obras públicas de edificações em Belo Horizonte. Inicialmente, o estudo envolveu uma análise quantitativa de aditivos de custos e prazos dessas obras ao longo dos seis últimos anos. Em um segundo momento, ocorreu uma análise qualitativa com os agentes envolvidos com esses empreendimentos, com a finalidade de estabelecer um ranking de possíveis causas, identificadas a partir da literatura. Os respondentes apontaram sua percepção sobre o impacto e frequência para uma lista de causas que afetam o prazo e o custo das obras, sendo os dados analisados pelo Índice de Importância Relativa (RII), Índice de Frequência (FI) e Índice de Importância (IMPI). Os resultados apontam que as principais causas dos aditivos contratuais de prazo e custo nas obras analisadas estão relacionadas às falhas no processo de projeto nas fases iniciais dos empreendimentos.

Palavras-chave: Empreendimentos públicos. Análise de custos e prazos. Processo de projeto.

\begin{abstract}
The poor performance of public construction projects with regards to cost overruns and delays has been recurrent in Brazil and other developing countries, and several research studies have focused on the analysis of the causes of deficient performance and have produced guidelines for project improvement. This study aims to present a diagnostic study on cost overruns and schedule delays in public projects in the city of Belo Horizonte. The first step of the study consisted of analysis of the costs and schedule problems for public projects over the past six years. In the second stage, interviews were conducted with stakeholders in order to establish a ranking of possible causes, based on literature research. Respondents indicated their perception of the impacts and frequency from a list of attributes that affect the timing and cost of projects. Interview data were analysed using the Relative Importance Index (RII), Frequency Index (FI) and Importance Index (IMPI). The results highlight that the main causes of cost overruns and schedule delays are highly related to design problems in the earlier stages of projects.
\end{abstract}

Recebido em 01/03/15 Aceito em 28/07/15

Paulo Roberto Pereira Andery
Universidade Federal de Minas Gerais Belo Horizonte - MG - Brasil

Keywords: Public projects. Cost and schedule analysis. Design process.

SANTOS, H. de P.; STARLING, C. M. D.; ANDERY, P. R. P. Um estudo sobre as causas de aumentos de custos e de prazos 225 em obras de edificações públicas municipais. Ambiente Construído, Porto Alegre, v. 15, n. 4, p. 225-242, out./dez. 2015.

ISSN 1678-8621 Associação Nacional de Tecnologia do Ambiente Construído. http://dx.doi.org/10.1590/s1678-86212015000400048 


\section{Introdução}

As crescentes exigências por obras de infraestrutura nos países em desenvolvimento, associadas ao aumento da complexidade dos projetos, têm gerado importantes desafios para a gestão de obras públicas. Entre os aspectos de destaque está o desafio de se criarem novas formas de contratação e gestão dos projetos que evitem os aumentos de custo e prazo de obras públicas (IYER; CHAPHALKAR; JOSHI, 2008). Não são poucos os países em desenvolvimento nos quais ocorrem significativos aumentos de custo e prazo nos projetos (ODEH; BATTAINEH, 2002), e o Brasil não é exceção.

Diversas são as causas que comprometem a implantação de empreendimentos dentro do planejamento físico e financeiro. Entre elas estão inconformidades e incompatibilidades nos projetos, interferências dos usuários e do contratante, construtoras despreparadas, falta de qualificação da mão de obra, fatores externos e falta de integração entre as etapas de projeto e obra (PEREIRA, 2012), em parte em função de entraves causados pelos mecanismos legais existentes, em particular a Lei 8.666/1993 (BRASIL, 1993).

Nesse contexto o presente trabalho apresenta uma análise sobre empreendimentos de edificações gerenciadas por uma autarquia pertencente a uma prefeitura municipal que incluem obras de implantação, reformas e ampliações, com foco na análise de causas para os aditamentos de custos e de prazos. O objeto específico de análise foi a determinação de até que ponto os empreendimentos estão sendo executados como planejados em termos de tempo e custo, e investigar as principais causas que geram os aditivos contratuais de prazo e valor.

A pesquisa é composta de um estudo exploratório inicial, com o objetivo de se ter uma visão de conjunto da gravidade do problema, realizando, em uma primeira etapa, estudo sobre a quantidade de obras com aditivos de valor e prazo, a intensidade dos valores de custo adicional nas obras e atrasos na execução dos empreendimentos. Em uma segunda etapa, realizou-se um estudo sobre as principais causas e suas contribuições para a geração dos aditivos contratuais de prazo e valor. A caracterização do valor e prazo dos aditivos, bem como das causas deles, é comparada às relatadas pela literatura internacional.

\section{Referencial teórico}

Estudos da literatura recente apontam para o fato de que os desvios de custos e prazos em relação aos valores definidos inicialmente pelos empreendedores têm sido recorrentes em vários países, principalmente entre os emergentes, ainda que não seja uma exclusividade destes. A título de exemplo, Doloi et al. (2012) relatam que os projetos de construção civil na Índia enfrentam atrasos generalizados. Al-Momani (2000) aponta que $81,5 \%$ das obras públicas na Jordânia sofreram atrasos. Já na Arábia Saudita, Assaf e Al-Hejji (2006) detectaram $70 \%$ de atrasos em diferentes tipos de construções. Segundo Aibinu e Jagboro (2002), os desvios de custo e de tempo de execução das obras tornaram-se comuns na Nigéria. Por outro lado, esses problemas têm sido também relatados em países com práticas de gestão de empreendimentos públicos mais eficientes (PROYER; GRIMSCHEID, 2013).

Pesquisas conduzidas em outros países sugerem que deficiências na etapa de concepção impactam fortemente no aumento de custos dos empreendimentos públicos. Nesse sentido, Ramabodu e Vester (2010) sugerem como fator mais crítico a modificação do escopo dos projetos durante sua execução. A isso se soma a realização das obras com projetos incompletos e com insuficiência de especificações. Resultados similares foram encontrados por Ardit, Akan e Gurdamar (1985) e Love et al. (2010). Cheng (2014) também identificou como fator mais crítico para aumentos de custos a mudança no escopo dos empreendimentos. Na mesma linha caminham os trabalhos de Creedy (2004) e Proyer e Grimscheid (2014), para os quais modificações nos projetos nas etapas finais da concepção impactam fortemente no aumento de custo e prazo. Mesmo em empreendimentos pautados pelo Design Build, que favorecem a integração entre projeto e obra, essa omissão e visão reducionista por parte de quem exerce o poder de compra vem sendo observada (KHALED; KARTAM, 2005).

No caso brasileiro sabe-se que a maior parte dos empreendimentos públicos tem seu processo de contratação e consequente gerenciamento balizado pela Lei 8.666/1993 (BRASIL, 1993), que tem sido objeto de críticas na literatura recente, principalmente pela ausência de integração entre as etapas de concepção e projeto (SANTOS et al., 2002; BRETAS, 2010; OLIVEIRA; MELHADO, 2002).

A literatura brasileira também tem apontado problemas associados à concepção e desenvolvimento dos projetos (BRETAS, 2010; PEREZ, 2011; PEREIRA, 2012). Mayr e Varvakis (2005) ressaltam a existência de ambiguidade na interpretação das informações do projeto como fator causador de aditivos contratuais. Conclusões 
semelhantes são encontradas tanto em trabalhos mais recentes como os de Canonico (2011) e Silva (2011) como em pesquisas mais antigas, como a de Brasiliano e Calmon (2000), indicando que os problemas são recorrentes. Pereira et al. (2011) relatam problemas de falta de mão de obra e dificuldades de gerenciar o cronograma.

Em uma visão mais sistêmica da questão, essas causas poderiam ser agrupadas em categorias distintas.

Um primeiro grupo de causas estaria associado a questões conjunturais no desenvolvimento dos empreendimentos (CHENG, 2014). Entre esses fatores podem ser destacados:

(a) condições ambientais adversas para a realização das obras;

(b) problemas macroeconômicos que gerem revisões contratuais por questões cambiais, inflacionárias, etc.;

(c) atrasos nos pagamentos aos empreiteiros por parte das empresas públicas, o que foi considerado por Gomes (2007) como problema frequente na realidade brasileira;

(d) questões laborais que podem gerar paralisações e custos adicionais (DOLOI et al., 2012); e

(e) flutuação no custo dos materiais (DOLOI et al., 2012).

Outro grupo de causas (CHENG, 2014; DOLOI et al., 2012) está associado a deficiências nos mecanismos de gestão dos empreendimentos na etapa de execução das obras. Entre os aspectos relatados estão os problemas relativos à ausência de mecanismos e procedimentos eficientes de fiscalização das obras ou à postura de pouco comprometimento por parte dos agentes públicos (RODRIGUES, 2010; PEREZ, 2011; CHENG, 2014; DOLOI et al., 2012). Outro ponto crítico diz respeito à ausência de mecanismos de planejamento financeiro antes da execução, além de controle e monitoramento de custos durante a execução (CHENG, 2014; DOLOI et al., 2012; RAMADOU; VESTER, 2010).

Um último grupo de causas estaria associado a aspectos políticos. $\mathrm{Na}$ literatura relatam-se situações nas quais, por pressões políticas, reduzse o prazo de concepção dos empreendimentos. A isso se somam ambientes de desenvolvimento de projetos nem sempre transparentes, conforme indicam Flyvbjerg, Holm e Buhl (2004).

Em linha similar de raciocínio, Rooke, Seymour e Fellows (2004) sugerem que parte dos pleitos contratuais e aditivos são antecipadamente planejados, ou decorrentes de uma lógica de contratos nos quais as partes já contam com os possíveis acréscimos de custo em relação aos valores previstos na licitação, em decorrência de vários fatores, cujo detalhamento foge ao escopo do trabalho. Em outras palavras, nem sempre aditivos e pleitos são decorrência de problemas de gestão dos processos de projeto e produção, podendo ser decorrentes da própria lógica contratual.

Uma relação de trabalhos indicada na Tabela 1 aponta a quantidade de possíveis causas de atrasos e aumentos de custos que alguns autores utilizaram em suas pesquisas. Também está indicado o número de possíveis categorias consideradas, ou seja, agrupamentos de causas associadas a um mesmo agente ou fator.

A partir do referencial teórico brevemente delineado anteriormente foram investigadas e analisadas as causas de atrasos e aumentos de custos em empreendimentos públicos de Belo Horizonte.

\section{Método de pesquisa}

A Figura 1 apresenta um fluxograma das etapas metodológicas a fim de elucidar o método adotado.

Em um primeiro momento desenvolveu-se uma revisão bibliográfica em âmbito internacional, focada no levantamento de valores e causas para os acréscimos de custos e prazos em empreendimentos de construção.

Como segunda etapa desenvolveu-se um estudo exploratório, levantando-se dados associados aos aditivos de custo e prazo. A pesquisa foi realizada em uma autarquia de direito público que é o principal órgão executor das obras de infraestrutura urbana e dos bens imóveis públicos da cidade de Belo Horizonte.

Inicialmente foram levantados os dados referentes aos aditivos contratuais de prazo e de valor ocorridos nas obras de edificações terminadas desde 2009 até as obras concluídas em 2014, totalizando 151 obras. As características de uso dessas obras são:
(a) 3 para administração;
(b) 2 para área ambiental;
(c) 6 para empreendimentos de cunho social;
(d) 73 para a área de educação;
(e) 3 destinadas ao lazer;
(f) 1 destinada ao setor de limpeza;
(g) 40 destinadas para a área da saúde;
(h) 2 destinadas ao setor de segurança; 
(i) 19 destinadas à área social; e

(j) 2 destinadas ao setor de transporte.

No primeiro tratamento dos dados verificou-se a quantidade de obras atingidas pelos aditivos contratuais de prazo e de valor separadamente. Em seguida, para se verificar a intensidade dos aditamentos, fez-se uma análise global em busca da média de aditivos de prazo e de valor nos 6 anos observados. Também foi calculada a média dos aditivos contratuais de valor e prazo separando-se as obras novas daquelas de reforma e/ou ampliação. Outra verificação feita foi em relação ao tipo de empreitada (preços unitários ou preço global). As obras foram separadas pelo tipo de empreitada, e então calculou-se a média dos aditamentos de prazo e valor para cada tipo de contrato praticado pela autarquia.

Tabela 1 - Resumo da metodologia adotada em trabalhos correlatos

\begin{tabular}{|c|c|c|c|c|c|}
\hline Autores & $\begin{array}{l}\mathrm{N}^{\circ} \text { de } \\
\text { causas }\end{array}$ & $\begin{array}{c}\mathrm{N}^{0} \text { de } \\
\text { categorias }\end{array}$ & $\begin{array}{l}\text { Escala } \\
\text { Likert }\end{array}$ & Estatística & Entrevistados \\
\hline Doloi et al. (2012) & $\begin{array}{c}45 \\
\text { (atraso) }\end{array}$ & 6 & 1 a 5 & RII & $\begin{array}{c}\text { Empreiteiros } \\
\text { Clientes } \\
\text { Engenheiros }\end{array}$ \\
\hline $\begin{array}{l}\text { Marzouk e El- } \\
\text { Rasas (2014) }\end{array}$ & $\begin{array}{c}43 \\
\text { (atraso) }\end{array}$ & 7 & 1 a 4 & $\begin{array}{l}\text { FI } \\
\text { SI }\end{array}$ & $\begin{array}{l}\text { Proprietários } \\
\text { Consultores } \\
\text { Empreiteiros }\end{array}$ \\
\hline $\begin{array}{l}\text { Sambasivan e } \\
\text { Soon (2007) }\end{array}$ & $\begin{array}{c}28 \\
\text { (atraso) }\end{array}$ & 8 & 1 a 5 & RII & $\begin{array}{c}\text { Clientes } \\
\text { Consultores } \\
\text { Empreiteiros }\end{array}$ \\
\hline $\begin{array}{c}\text { El-Razek, } \\
\text { Bassioni e } \\
\text { Mobarak (2008) }\end{array}$ & $\begin{array}{c}32 \\
\text { (atraso) }\end{array}$ & 3 & 0 a 3 & $\begin{array}{c}\text { RII } \\
\text { Spearman }\end{array}$ & $\begin{array}{l}\text { Proprietários } \\
\text { Consultores } \\
\text { Empreiteiros }\end{array}$ \\
\hline $\begin{array}{c}\text { Assaf e Al-Hejji } \\
(2006)\end{array}$ & $\begin{array}{c}73 \\
\text { (atraso) }\end{array}$ & 9 & 1 a 4 & $\begin{array}{c}\text { FI } \\
\text { SI } \\
\text { Spearman } \\
\end{array}$ & $\begin{array}{c}\text { Proprietários } \\
\text { Consultores } \\
\text { Empreiteiros }\end{array}$ \\
\hline $\begin{array}{c}\text { Lo, Fung e Tung } \\
\text { (2006) }\end{array}$ & $\begin{array}{c}30 \\
\text { (atraso) }\end{array}$ & 7 & 1 a 5 & $\begin{array}{l}\text { Pontuação } \\
\text { média MS }\end{array}$ & $\begin{array}{c}\text { Clientes } \\
\text { Consultores } \\
\text { Empreiteiros }\end{array}$ \\
\hline $\begin{array}{c}\text { Desai e Bhatt } \\
(2013)\end{array}$ & $\begin{array}{c}59 \\
\text { (atraso) }\end{array}$ & 9 & 1 a 4 & $\begin{array}{c}\text { RII } \\
\text { FI } \\
\text { IMPI } \\
\text { Spearman } \\
\end{array}$ & $\begin{array}{l}\text { Empreiteiros } \\
\text { Arquitetos } \\
\text { Proprietários }\end{array}$ \\
\hline $\begin{array}{l}\text { Gunduz, Nielsen e } \\
\text { Ozdemir (2015) }\end{array}$ & $\begin{array}{c}65 \\
\text { (atraso) }\end{array}$ & 7 & 1 a 5 & $\begin{array}{c}\text { RII } \\
\text { outras }\end{array}$ & $\begin{array}{l}\text { Consultores } \\
\text { Projetistas } \\
\text { Empreiteiros } \\
\text { Proprietários }\end{array}$ \\
\hline $\begin{array}{l}\text { Alaghbari, Kadir e } \\
\text { Ernawati (2007) }\end{array}$ & $\begin{array}{c}31 \\
\text { (atraso) }\end{array}$ & 4 & 4 a $1 *$ & $\begin{array}{l}\text { Pontuação } \\
\text { média MS }\end{array}$ & $\begin{array}{l}\text { Consultores } \\
\text { Empreiteiros } \\
\text { Proprietários }\end{array}$ \\
\hline $\begin{array}{l}\text { Enshassi, Al- } \\
\text { Najjar e } \\
\text { Kumaraswamy } \\
\text { (2009) }\end{array}$ & $\begin{array}{c}110 \\
\text { (atraso) }\end{array}$ & 12 & 0 a 4 & RII & $\begin{array}{l}\text { Consultores } \\
\text { Empreiteiros } \\
\text { Proprietários }\end{array}$ \\
\hline Tawil et al. (2013) & $\begin{array}{c}22 \\
\text { (atraso) }\end{array}$ & 0 & 1 a 5 & RII & $\begin{array}{c}\text { Consultores } \\
\text { Empreiteiros } \\
\end{array}$ \\
\hline Cheng (2014) & $\begin{array}{c}42 \\
\text { (custo) }\end{array}$ & 4 & 1 a 5 & RII & $\begin{array}{c}\text { Profissionais da } \\
\text { construção } \\
\text { Profissionais de controle } \\
\text { de custos }\end{array}$ \\
\hline $\begin{array}{c}\text { Enshassi, Al- } \\
\text { Najjar e } \\
\text { Kumaraswamy } \\
\text { (2009) }\end{array}$ & $\begin{array}{c}42 \\
\text { (custo) }\end{array}$ & 12 & 0 a 4 & RII & $\begin{array}{l}\text { Consultores } \\
\text { Empreiteiros } \\
\text { Proprietários }\end{array}$ \\
\hline
\end{tabular}

Nota: *esses autores utilizaram a escala inversa em relação aos demais, ou seja, 1 significa muito importante e 4 significa sem importância. 
Figura 1 - Fluxograma das etapas metodológicas

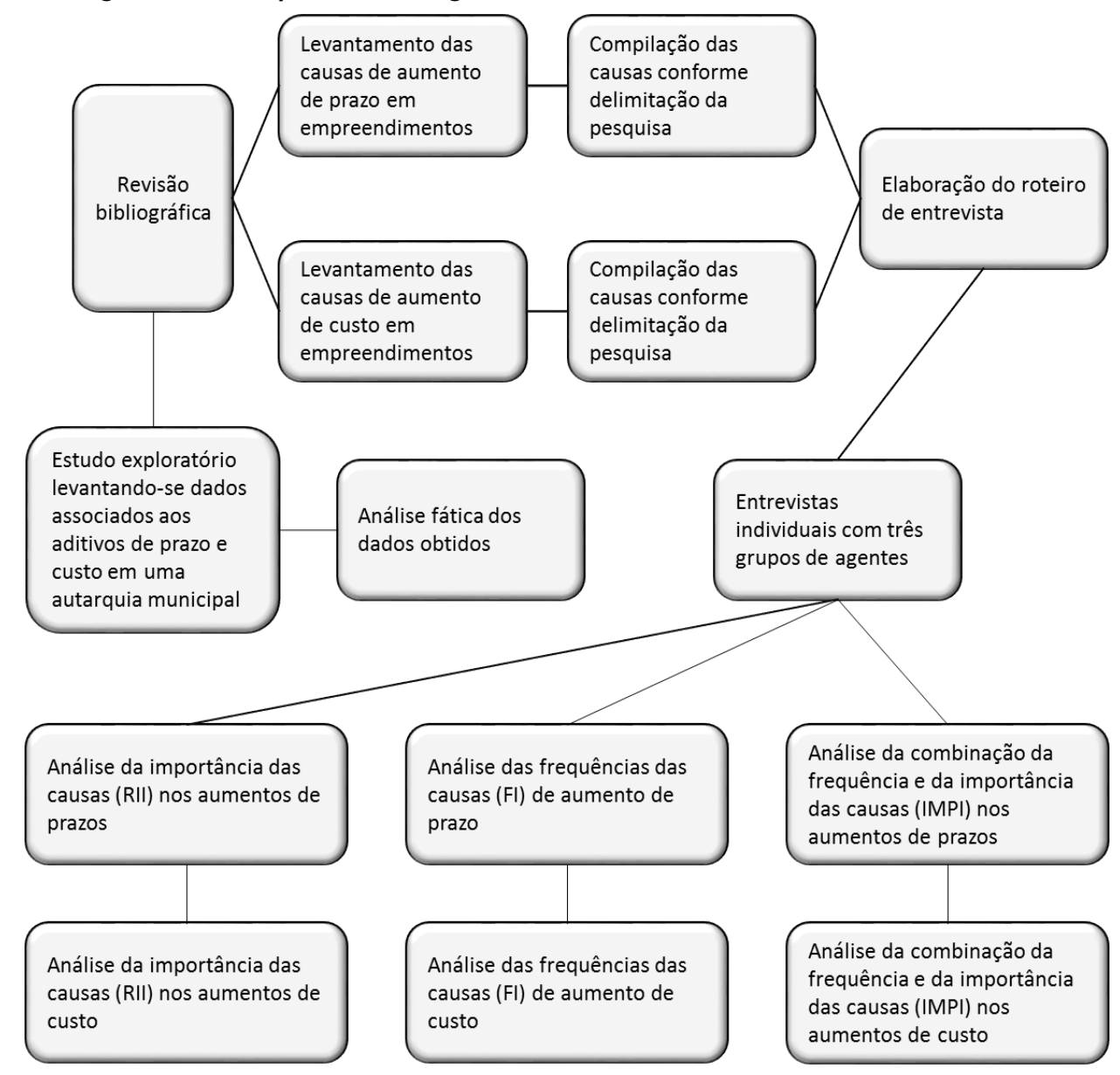

Para verificar se a finalidade do empreendimento influencia de alguma forma nos aditivos de valor e prazo, agruparam-se os dados por tipo de uso. As finalidades com menos de $10 \%$ das obras foram descartadas para essa comparação devido ao baixo número de dados. Em seguida calcularam-se as médias dos aditivos contratuais de prazo e valor para as demais áreas.

Os dados dos aditivos de valor foram separados por classes (ou faixas de valores) de superação de custo proposta por Shehu et al. (2014). Observouse qual era a frequência de aditivos em cada faixa.

Em uma terceira etapa da pesquisa elaborou-se um questionário para se avaliar a percepção das causas dos aditivos contratuais ocorridos na autarquia segundo três grupos de intervenientes entrevistados. Os possíveis fatores de aumentos de custo e prazo foram levantados a partir da revisão bibliográfica, sendo uma indicação dos trabalhos principais feita na Tabela 1, apresentada anteriormente.

O conjunto de causas de desvios de custos e prazos foi levantado dos trabalhos da literatura, os quais foram selecionados assumindo como critérios: (a) trabalhos envolvendo causas relacionadas a empreendimentos públicos de porte e tipologia semelhantes aos do presente estudo;

(b) trabalhos envolvendo causas aplicáveis à estrutura legal da realidade brasileira; e

(c) trabalhos que apresentaram um estudo estatístico a respeito das causas, de forma que uma comparação com a literatura internacional pudesse ser feita.

Todos os entrevistados eram engenheiros ou arquitetos, cujos perfis estão apresentados na Tabela 2.

O dimensionamento da amostra foi feito conforme proposto por Gil (1989) através da Equação 1.

$n=\frac{\sigma^{2} \mathrm{pq} \mathrm{N}}{e^{2}(N-1)+\sigma^{2} \mathrm{pq}}$

Eq. 1

Onde:

$n$ representa o dimensionamento da amostra;

$\sigma^{2}$ o nível de confiança escolhido expresso em número de desvios padrão;

$p$ a percentagem com a qual o fenômeno se verifica; 
$q$ a percentagem complementar (1-p); e

$N$ o tamanho da população e $e^{2}$ o erro máximo permitido.

Como a estimativa $p$ não estava previamente estabelecida, utilizou-se o valor máximo, que é de $50 \%$. Adotou-se um nível de confiança de $95,5 \%$ (que corresponde a 2 desvios padrão), e o erro máximo permitido de $10 \%$. O tamanho da população é 151 .

O número de obras calculado para se alcançarem os padrões desejados foi de 60 , portanto se procurou entrevistar determinado número de profissionais que tivessem atuado em mais de 60 das 151 obras investigadas. Observa-se na Tabela 2 que com 10 entrevistados de cada grupo superase o número desejado de atuações nas obras em questão.

Na Tabela 2 os supervisores das obras eram profissionais pertencentes à contratante, que acompanham diariamente as diversas obras na fase de execução.

O segundo grupo de entrevistados era formado pelos supervisores de projetos, que também eram profissionais pertencentes ao órgão público e que acompanham os empreendimentos que estão na fase de projeto. Atuavam ainda como os responsáveis para resolver as questões que envolvem os projetos das obras que estavam em execução.

O terceiro grupo de entrevistados era formado pelos engenheiros residentes, responsáveis técnicos pela execução das obras. Eram profissionais pertencentes ao quadro de funcionários das empreiteiras que executavam as obras.

O questionário foi dividido em três partes. A primeira continha informações do respondente, com a finalidade de identificar seu tempo de experiência na função e em quantas obras da autarquia pesquisada atuou. A segunda parte concentrou-se nas causas dos aditivos de prazo, e a terceira discorreu sobre as causas dos aditivos contratuais de valor.

A partir da análise bibliográfica foram levantadas 87 diferentes causas associadas aos aumentos de prazos dos empreendimentos, além de 69 para os aumentos de custos. Esse conjunto de causas serviu de base para elaboração de questionário. Descartaram-se as causas fora do contexto regional do estudo e também as que se encontravam fora das delimitações da pesquisa.

O objetivo básico das entrevistas foi o de solicitar por parte dos entrevistados uma hierarquização das causas, como indicado na sequência. Um questionário piloto foi aplicado a engenheiros e arquitetos da autarquia para validação. Após ajustes foram identificadas 64 causas de atrasos e 17 causas de aumentos de custos nas obras, que foram inseridas no roteiro da entrevista, sendo ainda deixado um local reservado para se adicionarem outras causas de atrasos em obras se o entrevistado achasse que estivessem faltando no questionário. As causas foram organizadas em oito categorias de opções: contratantes, projetistas, empreiteiras, materiais, mão de obra, equipamentos, empreendimentos e fatores externos.

Para a segunda e terceira parte do questionário foi inserida uma escala Likert de quatro pontos, e os engenheiros e arquitetos entrevistados foram convidados a informar sua percepção de impacto e frequência para cada causa. As possíveis respostas na escala de impacto foram:
(a) impacta muito (3);
(b) impacta consideravelmente (2);
(c) impacta pouco (1); e
(d) não tem impacto (0).

\section{Tabela 2 - Perfis dos grupos de entrevistados}

\begin{tabular}{ccccc}
\hline $\begin{array}{c}\text { Grupo de } \\
\text { entrevistados }\end{array}$ & $\begin{array}{c}\text { Quanti- } \\
\text { dade }\end{array}$ & $\begin{array}{c}\text { Tempo médio na } \\
\text { função (anos) }\end{array}$ & $\begin{array}{c}\text { Participação em obras da } \\
\text { autarquia de 2009 a 2014 }\end{array}$ & $\begin{array}{c}\text { Tempo médio da } \\
\text { entrevista (minutos) }\end{array}$ \\
\hline $\begin{array}{c}\text { Supervisores de } \\
\text { projetos }\end{array}$ & 10 & 4,2 & 71 & 34 \\
\hline $\begin{array}{c}\text { Supervisores de } \\
\text { obras }\end{array}$ & 10 & 7,9 & 120 & 40 \\
\hline $\begin{array}{c}\text { Engenheiros } \\
\text { residentes }\end{array}$ & 10 & 12,7 & 78 & 46 \\
\hline
\end{tabular}


O objetivo dessa escala é captar a percepção do entrevistado quanto à importância das causas na geração de aditivos de prazo e de valor. Também se introduziu uma escala para se captar a frequência de cada uma das causas. Essa escala variou da seguinte maneira:

(a) muito frequente (3);

(b) frequente (2);

(c) pouco frequente (1); e

(d) não acontece (0).

Utilizou-se a escala Likert variando de 0 a 3 por julgar que o 0 melhor representaria a situação em que determinada causa não contribuiria de forma alguma para a geração de aditivos contratuais de prazo ou valor. Esse procedimento alinha-se com os surveys realizados por outros pesquisadores, relacionados na Tabela 1, apresentada anteriormente.

Para cada atributo o entrevistado foi convidado a informar sua percepção em uma escala de importância e outra de frequência para as obras da autarquia nas quais ele havia atuado no período de 2009 a 2014. Conforme já explicado, foram entrevistados 10 engenheiros ou arquitetos de cada grupo. Entre os 10 engenheiros residentes, procurou-se escolher profissionais de várias construtoras e com variados anos de experiência. A entrevista presencial possibilitou impedir erros na transcrição das ideias ou na interpretação das questões. Os resultados das entrevistas foram tabulados considerando a intensidade e frequência que cada atributo recebeu na escala Likert.

O Índice de Importância Relativa (RII), também chamado por alguns autores indicados na Tabela 1 como Índice de Severidade (SI), é definido pela Equação 2.

$\mathrm{RII}=\mathrm{SI}=\sum \frac{\mathrm{w}}{A * N}$

Eq. 2

Onde:

$W$ é o peso dado a cada um dos fatores pelos respondentes, variando conforme a escala Likert;

$A$ é o peso mais elevado; e

$N$ é o número total de respondentes.

$\mathrm{O}$ valor de RII tem uma gama de 0 a 1 ; quanto mais próximo de 0 menos importante é a causa dos atrasos ou dos acréscimos nos custos, e quanto mais próximo de 1 mais importante é a causa.

Também foi calculado, seguindo o método proposto por alguns autores relacionados na Tabela 1, o Índice de Frequência (FI), definido pela Equação 3.
$\mathrm{FI}=\sum \frac{A_{f}}{A * N}$

Eq. 3

Onde:

$A_{f}$ é o peso da frequência dado a cada uma das causas pelos respondentes, variando conforme a escala Likert;

$A$ é o peso mais elevado; e

$N$ é o número total de respondentes.

Foi elaborado um ranking para cada grupo de entrevistados, além de um geral, de forma a se compararem os apontamentos entre os grupos e também dos três grupos em conjunto. Foi também estabelecido o Índice de Importância (IMPI), conforme alguns autores indicados na Tabela 1 , definido pela Equação 4.

$\mathrm{IMPI}=F I * R I I$

Eq. 4

Por fim, calculou-se o coeficiente de correlação de Spearman. Assaf e Al-Hejji (2006) explicam que a correlação de Spearman é um teste não paramétrico, também referido como teste de distribuição livre. Os testes de distribuição livre têm a vantagem de não exigir o pressuposto de normalidade ou a suposição de homogeneidade de variância.

\section{Resultados e discussão}

\section{Visão global dos aditivos}

A autarquia aqui pesquisada concluiu 151 obras de edificações de 2009 até 2014. Os dados completos referentes a essas obras e aos respectivos aditivos contratuais de prazo e de valor são omitidos por brevidade, podendo ser vistos com detalhes em Santos (2015). Em uma análise quantitativa verificou-se que dessas obras 145 contaram com aditivos de prazo, ou seja, 96\%, e 109 obras tiveram aditivos de valor, representando $72 \%$. Assim, percebe-se que os aditivos contratuais atingiram praticamente todas as obras dessa entidade pública. A Tabela 3 apresenta os resultados da quantidade de obras atingidas pelos aditivos de custo e de prazo, os valores médios de acréscimos e uma comparação com trabalhos de outros autores. Observa-se que os resultados estão acima dos relatados em outras pesquisas, com exceção da intensidade de aumento de custo, que se aproxima dos encontrados na Nigéria e em Taiwan.

$\mathrm{Na}$ análise de intensidade, também mostrada na Tabela 3, em média, os empreendimentos levaram mais que o dobro do tempo inicialmente previsto. Por outro lado, os acréscimos de valor dessas obras foram abaixo do limite permitido pela Lei de Licitações (BRASIL, 1993), que é de $25 \%$ para 
empreendimentos novos e de $50 \%$ para obras de reformas.

Entre os empreendimentos da autarquia concluídos no período analisado, 70 foram obras novas e 81 obras de reforma e/ou ampliação. Em geral, a média dos acréscimos de prazo foi de $90 \%$ para obras de implantação e de $125 \%$ para obras de reforma e/ou ampliação. Já os acréscimos de valor foram de $12 \%$ para as obras de implantação e $20 \%$ para as obras de reforma e/ou ampliação. Portanto, os empreendimentos novos apresentaram melhores resultados tanto para prazos quanto para custos. Entre as obras consideradas da autarquia, 114 foram contratadas a preços unitários e tiveram intensidade média de $121 \%$ de acréscimos contratuais de prazo, contra $71 \%$ de acréscimos nas demais 37 obras de empreitada a preço global. Em termos dos aditivos de valores, os contratos de obras a preços unitários apresentaram intensidade média de $20 \%$ de acréscimos no custo, contra $6 \%$ de acréscimos para as obras a preço global. Portanto, os empreendimentos contratados a preço global apresentaram melhores resultados tanto para prazos quanto para custos.

Verificou-se que os acréscimos médios de prazos foram semelhantes para as obras com finalidades educacional e social, sendo os acréscimos para as obras da área da saúde cerca de $30 \%$ superiores.
Uma possível explicação discutida com alguns profissionais da autarquia descartou a possibilidade de os maiores atrasos serem decorrentes da maior complexidade das obras do segmento da saúde, considerando como provável causa o fato de ter havido maiores atrasos nos pagamentos dos empreiteiros dessas obras.

Em relação aos aditivos de valor, os empreendimentos da área da educação apresentaram acréscimos médios de custos correspondentes a cerca de dois terços daqueles observados para as obras das áreas da saúde e social. A situação encontrada na autarquia foi oposta à observada por Shehu et al. (2014). Na Malásia, os empreendimentos da saúde tiveram o melhor desempenho em termos de ser concluídos dentro do valor inicial do contrato, enquanto os projetos educacionais apresentaram o pior desempenho.

A Tabela 4 apresenta a análise da frequência das classes de intensidades definidas por Shehu et al. (2014) para os acréscimos de valores das 151 obras da autarquia. Embora 28,5\% dos empreendimentos (43 obras) não tenham apresentado acréscimos de valores, os números encontrados estão bem abaixo daqueles relatados por Shehu et al. (2014), alcançados pelo setor público na Malásia.

Tabela 3 - Comparação entre a presente pesquisa e trabalhos de outros autores

\begin{tabular}{ccccc}
\hline Comparação & $\begin{array}{c}\text { Presente } \\
\text { pesquisa }\end{array}$ & $\begin{array}{c}\text { Outra } \\
\text { pesquisa }\end{array}$ & Autores & País \\
\hline $\begin{array}{c}\text { Obras com acréscimo de } \\
\text { prazo }\end{array}$ & $96 \%$ & $70 \%$ & Assaf e Al-Hejji (2006) & Arábia Saudita \\
\cline { 3 - 5 } $\begin{array}{c}\text { Obras com acréscimo de } \\
\text { custo }\end{array}$ & $72 \%$ & $55 \%$ & Shehu et al. (2014) & Malásia \\
\hline $\begin{array}{c}\text { Intensidade de aumento de } \\
\text { prazo }\end{array}$ & $109 \%$ & $40 \%$ & $\begin{array}{c}\text { Arditi, Akan e Gurdamar } \\
(1985)\end{array}$ & Turquia \\
\cline { 3 - 5 } & 10 a 30\% & Assaf e Al-Hejji (2006) & Arábia Saudita \\
\hline $\begin{array}{c}\text { Intensidade de aumento de } \\
\text { custo }\end{array}$ & $16 \%$ & $17,34 \%$ & Aibinu e Jagboro (2002) & Nigéria \\
\hline
\end{tabular}

Tabela 4 - Aditivos contratuais de valor por classes de superação do orçado

\begin{tabular}{cccc}
\hline \multirow{2}{*}{$\begin{array}{c}\text { Classe de } \\
\text { acréscimo do valor }\end{array}$} & \multicolumn{2}{c}{ Frequência do presente estudo } & Frequência (Shehu et al. (2014)) \\
\cline { 2 - 4 }$(\boldsymbol{\%})$ & $\begin{array}{c}\text { Número de } \\
\text { obras }\end{array}$ & $\begin{array}{c}\text { Percentual de } \\
\text { obras }\end{array}$ & $\begin{array}{c}\text { Percentual de } \\
\text { obras }\end{array}$ \\
\hline$<0$ & 1 & $0,7 \%$ & $44,5 \%$ \\
0 & 42 & $27,8 \%$ & $1,3 \%$ \\
0,1 a $5 \%$ & 12 & $7,9 \%$ & $20,1 \%$ \\
5,1 a $10 \%$ & 13 & $8,6 \%$ & $10,1 \%$ \\
10,1 a $20 \%$ & 24 & $15,9 \%$ & $16,2 \%$ \\
20,1 a 30\% & 32 & $21,2 \%$ & $3,6 \%$ \\
$>30 \%$ & 27 & $17,9 \%$ & $4,2 \%$ \\
Total & 151 & $100,0 \%$ & $100 \%$ \\
\hline
\end{tabular}

232 Santos, H. de P.; Starling, C. M. D.; Andery, P. R. P. 


\section{Estudo das causas de atrasos nas obras da autarquia}

Para uma melhor apresentação dos resultados das entrevistas foi necessário organizar as causas de acréscimos de prazo das obras pelos índices de identificação apresentados na Tabela 5. Os resultados das entrevistas sobre as causas dos aditivos de prazo nas obras da autarquia foram tabulados a partir de um ranking definido em ordem decrescente dos fatores RII, FI e IMPI das causas dos atrasos. As Tabelas 6, 7 e 8 apresentam, na visão geral do conjunto dos três grupos de agentes entrevistados, as dez primeiras causas de atrasos em termos de RII, FI e IMPI respectivamente, também indicando o ranking dessas causas para cada um dos grupos. O conjunto de dados e demais cálculos são omitidos por razões de brevidade, podendo ser vistos com detalhes em Santos (2015).

Conforme a Tabela 6, considerando o conjunto dos três grupos de entrevistados, as cinco causas com maior potencial para afetar o prazo dos empreendimentos foram, em ordem decrescente de RII:

(a) "duração do contrato irrealista";

(b) "falta de compatibilização dos projetos";

(c) "atraso em revisões e aprovações de documentos de projeto pelo contratante";

(d) "erros nos levantamentos de quantitativos/planilha"; e

(e) "erros nas investigações de solo".

Ainda que os três grupos de agentes entrevistados tenham ressaltado alguns pontos em comum com os outros, o ranking segundo o RII aponta para resultados diferentes. Mesmo que algumas causas apontadas por cada grupo possam estar dentro de sua área de atuação e controle, parece haver uma tendência de ressaltar problemas que dizem respeito a outra esfera de atuação. Esse tipo de comportamento foi relatado também em trabalho recente (MCGRAW..., 2014), e uma possível explicação está no fato de que os agentes tendem a criar mecanismos de defesa no que diz respeito a suas responsabilidades, ficando mais fácil evidenciar problemas fora de sua área de atuação. Essa tendência também aponta para o fato, relatado na literatura recente, de uma visão segmentada ou compartimentalizada dos empreendimentos, em que faltam aos agentes uma visão de todo o empreendimento, além de uma percepção a respeito da responsabilidade conjunta como indutora da colaboração e melhoria do resultado dos projetos, como apontado por Shelbourn et al. (2012).

As respostas a respeito das causas de aumentos dos prazos foram hierarquizadas na Tabela 7 tomando como parâmetro o FI. Na opinião dos três grupos juntos, as cinco causas que acontecem com maior frequência são, em ordem decrescente:

(a) "erros nos levantamentos de quantitativos/planilha";

(b) "falta de compatibilização dos projetos";

(c) "atraso na finalização de preços para itens extras";

(d) "atraso por parte do contratante nos pagamentos dos trabalhos executados pelo empreiteiro"; e

(e) "duração do contrato irrealista".

Observa-se que os resultados para FI individualizando os grupos de agentes são mais homogêneos entre os grupos do que os resultados de RII. Parece que nesse ponto predominam mais as observações dos fatos ocorridos, e menos a tendência de evidenciar problemas fora de cada área de atuação.

Entre as dez causas mais frequentes (com maior FI), observa-se que quatro são motivadas pelo contratante, cinco pelos projetistas e apenas uma pelas empreiteiras. Essas mesmas causas coincidem com as dez que causam maior impacto (maiores RII) no prazo das obras, embora não na mesma ordem do ranking. Essa combinação de frequência e impacto oferece grande potencial para resultar em atrasos nas obras da autarquia.

As combinações entre a frequência de ocorrência e o potencial de impacto para causar atrasos nas obras também foram analisados pelo IMPI, na Tabela 8. A análise dos resultados sugere que a causa que mais contribui para os atrasos nas obras da autarquia é a "compatibilização de projetos", seguido de "erros nos levantamentos de quantitativos". Essas duas causas são motivadas pelos projetistas, que normalmente são contratados pela autarquia para a elaboração dos documentos dos projetos. Portanto, o gerenciamento dos contratos de projetos e, principalmente, o recebimento desses serviços é o principal foco a ser tratado por essa entidade pública. A situação encontrada na autarquia é bem semelhante à relatada por Al-Momani (2000), o qual observou em seu estudo que $81,5 \%$ das obras públicas analisadas sofreram atrasos, sendo a má concepção em projetos confirmada como a principal causa. 
Tabela 5 - Causas de atrasos nas obras (continua)

\begin{tabular}{|c|c|c|}
\hline Motivador & Índice & Causa dos aditivos contratuais de prazo \\
\hline \multirow{15}{*}{ Contratante } & $\mathrm{CO}-1$ & Tomada de decisão lenta pelo contratante \\
\hline & $\mathrm{CO}-2$ & Suspensão do trabalho pelo contratante \\
\hline & $\mathrm{CO}-3$ & Atraso em revisões e aprovações de documentos de projeto pelo contratante \\
\hline & $\mathrm{CO}-4$ & Atraso na finalização de preços para itens extras \\
\hline & $\mathrm{CO}-5$ & Atraso na liberação do local para o empreiteiro \\
\hline & $\mathrm{CO}-6$ & $\begin{array}{l}\text { Atraso por parte do contratante nos pagamentos dos trabalhos executados pelo } \\
\text { empreiteiro }\end{array}$ \\
\hline & $\mathrm{CO}-7$ & Alterações de escopo pelo proprietário durante a construção \\
\hline & $\mathrm{CO}-8$ & Licitação pelo menor preço \\
\hline & $\mathrm{CO}-9$ & Tipo de contrato de construção (Turnkey, preços unitários, preço global, etc.) \\
\hline & $\mathrm{CO}-10$ & Duração do contrato irrealista \\
\hline & $\mathrm{CO}-11$ & Penalidades de atraso ineficazes ou inexistentes \\
\hline & $\mathrm{CO}-12$ & Interferência do usuário \\
\hline & $\mathrm{CO}-13$ & Falta de um representante capaz \\
\hline & $\mathrm{CO}-14$ & Interferência no processo de construção ou alteração de sequência \\
\hline & $\mathrm{CO}-15$ & Erros, omissões ou inconsistências no caderno de encargos \\
\hline \multirow{12}{*}{ Projetistas } & PR-1 & Falta de experiência dos projetistas e consultores \\
\hline & PR-2 & Complexidade da concepção do projeto \\
\hline & PR-3 & Não uso de software de projeto de engenharia avançado \\
\hline & PR-4 & Erros nas investigações de solo \\
\hline & PR-5 & Coleta de dados insuficientes antes de projetar \\
\hline & PR-6 & Erros e discrepâncias nos documentos de projeto \\
\hline & PR-7 & Detalhes pouco claros e inadequados em projetos \\
\hline & PR-8 & Falta de compatibilização dos projetos \\
\hline & PR-9 & Falta de especificações nos projetos \\
\hline & PR-10 & Falta de padronização dos projetos \\
\hline & PR-11 & Má representação dos projetos \\
\hline & PR-12 & Erros nos levantamentos de quantitativos/planilha \\
\hline \multirow{12}{*}{ Empreiteira } & EA-1 & Dificuldades de financiamento pelo empreiteiro \\
\hline & EA-2 & Má gestão do canteiro de obras e acompanhamento responsável obra \\
\hline & EA-3 & Planejamento e cronograma da obra ineficaz \\
\hline & EA-4 & Falta de banco de dados para estimar a duração e recursos atividade \\
\hline & EA-5 & Retrabalho devido a erros durante a construção \\
\hline & EA-6 & Atrasos no trabalho de subempreiteiros \\
\hline & EA-7 & Experiência inadequada do empreiteiro \\
\hline & EA-8 & Atraso na mobilização da obra \\
\hline & EA-9 & Atraso na elaboração de projetos (responsabilidade do empreiteiro) \\
\hline & EA-10 & Métodos construtivos inadequados utilizados pela contratada \\
\hline & EA-11 & Preços muito baixos apresentados na licitação \\
\hline & EA-12 & Atrasos em ensaios e testes \\
\hline \multirow{4}{*}{ Materiais } & MA-1 & A escassez de materiais de construção no mercado \\
\hline & MA-2 & Atraso na entrega de material \\
\hline & MA-3 & $\begin{array}{l}\text { Alterações nos tipos de materiais e especificações por parte do fabricante } \\
\text { durante a construção }\end{array}$ \\
\hline & MA-4 & Qualidade dos materiais \\
\hline \multirow{6}{*}{ Mão de obra } & MO-1 & A escassez de mão de obra \\
\hline & MO-2 & Força de trabalho não qualificada \\
\hline & MO-3 & Baixo nível de produtividade do trabalho \\
\hline & $\mathrm{MO}-4$ & Conflitos pessoais entre os trabalhadores \\
\hline & MO-5 & Baixa motivação do trabalhador \\
\hline & MO-6 & Greve \\
\hline
\end{tabular}


Tabela 5 - Causas de atrasos nas obras (continuação)

\begin{tabular}{lll}
\hline \multirow{4}{*}{ Equipamentos } & EQ-1 & Falta de disponibilidade de equipamentos \\
\cline { 2 - 3 } & EQ-2 & Má estado de conservação de equipamentos \\
\cline { 2 - 3 } & EQ-3 & Baixa produtividade e eficiência dos equipamentos \\
\hline \multirow{4}{*}{ Empreendimento } & Baixa tecnologia de equipamentos mecânicos \\
\cline { 2 - 3 } & EO-1 & Efeitos das condições do subsolo \\
\cline { 2 - 3 } & EO-2 & Controle e restrição de tráfego no local de trabalho \\
\cline { 2 - 3 } & EO-4 & Indisponibilidade de serviços públicos no local, tais como água, luz, etc. \\
\hline \multirow{4}{*}{ Externas } & EO-5 & Problema com vizinhos \\
\hline & EX-2 & Efeito do tempo (quente, chuva, etc.) \\
\cline { 2 - 3 } & EX-3 & Mudaço̧as nos ambientais \\
\hline & EX-4 & Atraso na prestação de serviços de utilidades por concessionárias, tais como \\
\cline { 2 - 3 } & EX-5 & Autorização lenta por parte do governo e autoridades \\
\cline { 2 - 3 } & EX-6 & Falta de comunicação entre as partes \\
\hline
\end{tabular}

Tabela 6 - Ranking de RII para prazo

\begin{tabular}{ccccccccc}
\hline Atributo & $\begin{array}{c}\text { Supervisor de } \\
\text { projetos }\end{array}$ & \multicolumn{2}{c}{$\begin{array}{c}\text { Supervisor de } \\
\text { obras }\end{array}$} & $\begin{array}{c}\text { Engenheiros } \\
\text { residentes }\end{array}$ & \multicolumn{2}{c}{ Todos } \\
\hline Índice & RII & Ranking & RII & Ranking & RII & Ranking & RII & Ranking \\
\hline CO-10 & 0,600 & 15 & 1,000 & 1 & 0,700 & 3 & 0,767 & 1 \\
PR-8 & 0,767 & 4 & 0,867 & 2 & 0,667 & 5 & 0,767 & 2 \\
CO-3 & 0,667 & 11 & 0,767 & 9 & 0,800 & 1 & 0,744 & 3 \\
PR-12 & 0,733 & 7 & 0,767 & 8 & 0,733 & 2 & 0,744 & 4 \\
PR-4 & 0,800 & 2 & 0,733 & 10 & 0,667 & 6 & 0,733 & 5 \\
EA-3 & 0,733 & 8 & 0,867 & 3 & 0,567 & 13 & 0,722 & 6 \\
CO-1 & 0,800 & 1 & 0,633 & 14 & 0,667 & 8 & 0,700 & 7 \\
PR-6 & 0,600 & 17 & 0,867 & 5 & 0,633 & 9 & 0,700 & 8 \\
PR-5 & 0,700 & 9 & 0,867 & 4 & 0,533 & 18 & 0,700 & 9 \\
CO-4 & 0,733 & 6 & 0,800 & 6 & 0,533 & 19 & 0,689 & 10 \\
\hline
\end{tabular}

Tabela 7 - Ranking de FI para prazo

\begin{tabular}{ccccccccc}
\hline Atributo & $\begin{array}{c}\text { Supervisor de } \\
\text { projetos }\end{array}$ & $\begin{array}{c}\text { Supervisor de } \\
\text { obras }\end{array}$ & $\begin{array}{c}\text { Engenheiros } \\
\text { residentes }\end{array}$ & Todos \\
\hline Índice & FI & Ranking & FI & Ranking & FI & Ranking & FI & Ranking \\
\hline PR-12 & 0,800 & 2 & 1,000 & 1 & 0,800 & 4 & 0,867 & 1 \\
PR-8 & 0,867 & 1 & 0,867 & 4 & 0,833 & 3 & 0,856 & 2 \\
CO-4 & 0,767 & 3 & 0,833 & 5 & 0,867 & 2 & 0,822 & 3 \\
CO-6 & 0,567 & 12 & 0,900 & 3 & 0,867 & 1 & 0,778 & 4 \\
CO-10 & 0,667 & 6 & 1,000 & 2 & 0,667 & 8 & 0,778 & 5 \\
CO-3 & 0,567 & 11 & 0,800 & 7 & 0,700 & 5 & 0,689 & 6 \\
PR-6 & 0,533 & 14 & 0,800 & 9 & 0,700 & 6 & 0,678 & 7 \\
PR-5 & 0,700 & 5 & 0,800 & 6 & 0,533 & 16 & 0,678 & 8 \\
EA-3 & 0,567 & 13 & 0,800 & 8 & 0,633 & 10 & 0,667 & 9 \\
PR-4 & 0,733 & 4 & 0,700 & 11 & 0,500 & 22 & 0,644 & 10 \\
\hline
\end{tabular}


Tabela 8 - Ranking de IMPI para prazo

\begin{tabular}{ccccccccc}
\hline Atributo & \multicolumn{2}{c}{$\begin{array}{c}\text { Supervisor de } \\
\text { projetos }\end{array}$} & \multicolumn{2}{c}{$\begin{array}{c}\text { Supervisor de } \\
\text { obras }\end{array}$} & \multicolumn{2}{c}{$\begin{array}{c}\text { Engenheiros } \\
\text { residentes }\end{array}$} & \multicolumn{2}{c}{ Todos } \\
\hline Índice & IMPI & Ranking & IMPI & Ranking & IMPI & Ranking & IMPI & Ranking \\
\hline PR-8 & 0,664 & 1 & 0,751 & 3 & 0,556 & 3 & 0,656 & 1 \\
PR-12 & 0,587 & 2 & 0,767 & 2 & 0,587 & 1 & 0,645 & 2 \\
CO-10 & 0,400 & 9 & 1,000 & 1 & 0,467 & 5 & 0,596 & 3 \\
CO-4 & 0,562 & 4 & 0,667 & 8 & 0,462 & 7 & 0,566 & 4 \\
CO-6 & 0,359 & 12 & 0,720 & 4 & 0,491 & 4 & 0,519 & 5 \\
CO-3 & 0,378 & 11 & 0,613 & 9 & 0,560 & 2 & 0,513 & 6 \\
EA-3 & 0,416 & 8 & 0,693 & 6 & 0,359 & 13 & 0,481 & 7 \\
PR-6 & 0,320 & 15 & 0,693 & 7 & 0,443 & 8 & 0,474 & 8 \\
PR-5 & 0,490 & 5 & 0,693 & 5 & 0,284 & 19 & 0,474 & 9 \\
PR-4 & 0,587 & 3 & 0,513 & 10 & 0,333 & 14 & 0,473 & 10 \\
\hline
\end{tabular}

Ainda segundo o fator IMPI, a causa em terceiro lugar na geração de aditivos de prazo é a "duração irrealista dos contratos". De fato, foi comentada por alguns profissionais nas entrevistas a possibilidade de se reduzir o prazo de execução de uma obra para se encaixar no orçamento pretendido, principalmente através da redução dos Benefícios e Despesas Indiretas (BDI). A quarta causa que mais contribui para os atrasos nas obras é o "atraso na finalização de preços para itens extras". Essa causa é uma consequência da segunda principal motivadora de aditivos de prazo, pois, não havendo erros nos levantamentos de quantitativos, esse problema seria consideravelmente reduzido. De forma semelhante, a sexta causa geradora de aditivos de prazo é o "atraso em revisões e aprovações de documentos de projeto pelo contratante", que é consequência da falta de compatibilização e de erros em projetos. $\mathrm{Na}$ opinião dos entrevistados, a quinta maior causadora de aditivos de prazo está relacionada aos "atrasos de pagamentos pelo contratante". O órgão público precisa estar ciente de que os atrasos nos pagamentos das empreiteiras afetam fortemente o prazo da obra e, como consequência, aumentam os custos dos empreendimentos. Portanto, o pagamento em dia das empresas contratadas representa melhor uso dos recursos públicos.

Todos os valores dos coeficientes de correlação de Spearman entre os grupos de entrevistados ficaram acima de 0,7, o que é considerado por El-Razek, Bassioni e Mobarak (2008) como de alta concordância para as respostas. A maior concordância de respostas ocorreu entre os grupos dos "supervisores de projetos" e "supervisores de obras", com coeficiente de Spearman de 0,794. De forma similar, os grupos de "supervisores de obras" e "engenheiros das obras" apresentaram valor de 0,753 para o coeficiente de Spearman, enquanto os de "supervisores de projetos" e "engenheiros das obras" o valor de 0,718 .
Entre as dez principais causas, os resultados sugerem que a principal contribuição que as empreiteiras podem dar para redução dos acréscimos nos prazos das obras da autarquia é a implementação de melhorias em relação ao planejamento e cronograma das obras.

\section{Estudo das causas de desvios de custos das obras da autarquia}

Também para apresentação dos resultados das entrevistas, as causas de acréscimos de custo das obras em relação aos valores orçados foram organizadas por índices de identificação, apresentados na Tabela 9.

As Tabelas 10, 11 e 12 apresentam, na visão geral do conjunto dos três grupos de agentes entrevistados, as dez primeiras causas de aumento de custo em termos de RII, FI e IMPI respectivamente, também indicando o ranking dessas causas para cada um dos grupos. O conjunto de dados e demais cálculos são omitidos novamente por razões de brevidade, podendo ser vistos com detalhes em Santos (2015).

Conforme a Tabela 10, na opinião dos três grupos reunidos de entrevistados as causas que mais impactam em acréscimos de custos das obras da autarquia foram, em ordem decrescente de RII:

(a) "serviços não previstos no orçamento ou ausência de itens na planilha";

(b) "levantamento de quantitativos de serviços subestimados na planilha";

(c) "condições do subsolo inesperadas";

(d) "falhas em projetos ou projetistas inexperientes"; e

(e) "mudanças de escopo ou modificações em projetos durante a obra".

Essas causas coincidem com as cinco com maior importância em aumentos de custos das obras 
relatadas pelo grupo de supervisores de obras, embora não na mesma ordem de ranking. Outras causas que tiveram destaque entre as cinco primeiras do ranking de RII foram as "paralisações da obra", apontada no grupo de supervisores de projetos, e "falhas na gestão do tempo", no grupo dos engenheiros de obras.

Tabela 9 - Causas de desvios de custos nas obras

\begin{tabular}{cl}
\hline Índice & \multicolumn{1}{c}{ Causa dos aditivos contratuais de valor } \\
\hline A & Fator climático \\
B & Condições do subsolo inesperadas \\
C & Definição de escopo sem clareza \\
D & Mudanças de escopo ou modificações em projetos durante a obra \\
E & Paralisações da obra \\
F & Atualização de preços (reajustes/realinhamento) \\
G & Serviços não previstos no orçamento ou ausência de itens na planilha \\
H & Levantamento de quantitativos de serviços subestimados na planilha \\
I & Controle de custos ineficaz \\
J & Falhas na gestão do tempo \\
K & Pequeno orçamento de projeto (design) \\
L & Força maior (desastres naturais, inundações, deslizamentos de terra, etc.) \\
M & Preços muito baixos apresentados na licitação \\
N & Falhas em projetos ou projetistas inexperientes \\
O & Informações não claras, ambíguas e contraditórias em relação caderno encargos \\
P & Distribuição desequilibrada de risco entre o proprietário e empreiteiro \\
Q & Divisão pouco nítida responsabilidades e falta de requisitos de gestão profissional \\
\hline
\end{tabular}

Tabela 10 - Ranking de RII para custo

\begin{tabular}{ccccccccc}
\hline Atributo & \multicolumn{2}{c}{$\begin{array}{c}\text { Supervisor de } \\
\text { projetos }\end{array}$} & \multicolumn{2}{c}{$\begin{array}{c}\text { Supervisor de } \\
\text { obras }\end{array}$} & \multicolumn{2}{c}{$\begin{array}{c}\text { Engenheiros } \\
\text { residentes }\end{array}$} & \multicolumn{2}{c}{ Todos } \\
\hline Índice & RII & Ranking & RII & Ranking & RII & Ranking & RII & Ranking \\
\hline G & 0,900 & 1 & 0,900 & 1 & 0,733 & 3 & 0,844 & 1 \\
H & 0,867 & 2 & 0,867 & 2 & 0,767 & 2 & 0,833 & 2 \\
B & 0,733 & 3 & 0,667 & 4 & 0,633 & 5 & 0,678 & 3 \\
N & 0,533 & 8 & 0,733 & 3 & 0,733 & 4 & 0,667 & 4 \\
D & 0,633 & 5 & 0,667 & 5 & 0,633 & 6 & 0,644 & 5 \\
J & 0,533 & 7 & 0,500 & 7 & 0,867 & 1 & 0,633 & 6 \\
E & 0,667 & 4 & 0,467 & 9 & 0,533 & 8 & 0,556 & 7 \\
F & 0,400 & 11 & 0,600 & 6 & 0,600 & 7 & 0,533 & 8 \\
I & 0,500 & 9 & 0,500 & 8 & 0,467 & 10 & 0,489 & 9 \\
K & 0,367 & 12 & 0,467 & 10 & 0,500 & 9 & 0,444 & 10 \\
\hline
\end{tabular}

Tabela 11 - Ranking de FI para custo

\begin{tabular}{ccccccccc}
\hline Atributo & \multicolumn{2}{c}{$\begin{array}{c}\text { Supervisor de } \\
\text { projetos }\end{array}$} & \multicolumn{2}{c}{$\begin{array}{c}\text { Supervisor de } \\
\text { obras }\end{array}$} & \multicolumn{2}{c}{$\begin{array}{c}\text { Engenheiros } \\
\text { residentes }\end{array}$} & \multicolumn{2}{c}{ Todos } \\
\hline Índice & FI & Ranking & FI & Ranking & FI & Ranking & FI & Ranking \\
\hline H & 0,933 & 1 & 0,867 & 2 & 0,733 & 1 & 0,844 & 1 \\
G & 0,933 & 2 & 0,867 & 1 & 0,700 & 2 & 0,833 & 2 \\
N & 0,567 & 5 & 0,633 & 3 & 0,667 & 3 & 0,622 & 3 \\
J & 0,600 & 4 & 0,500 & 6 & 0,667 & 4 & 0,589 & 4 \\
B & 0,633 & 3 & 0,400 & 7 & 0,533 & 7 & 0,522 & 5 \\
F & 0,433 & 9 & 0,567 & 4 & 0,533 & 5 & 0,511 & 6 \\
D & 0,467 & 7 & 0,500 & 5 & 0,533 & 6 & 0,500 & 7 \\
K & 0,333 & 11 & 0,400 & 10 & 0,500 & 8 & 0,411 & 8 \\
I & 0,400 & 10 & 0,400 & 9 & 0,433 & 10 & 0,411 & 9 \\
E & 0,533 & 6 & 0,400 & 8 & 0,300 & 11 & 0,411 & 10 \\
\hline
\end{tabular}


Tabela 12 - Ranking de IMPI para custo

\begin{tabular}{ccccccccc}
\hline Atributo & \multicolumn{2}{c}{$\begin{array}{c}\text { Supervisor de } \\
\text { projetos }\end{array}$} & \multicolumn{2}{c}{$\begin{array}{c}\text { Supervisor de } \\
\text { obras }\end{array}$} & \multicolumn{2}{c}{$\begin{array}{c}\text { Engenheiros } \\
\text { residentes }\end{array}$} & \multicolumn{2}{c}{ Todos } \\
\hline Índice & IMPI & Ranking & IMPI & Ranking & IMPI & Ranking & IMPI & Ranking \\
\hline H & 0,809 & 2 & 0,751 & 2 & 0,562 & 2 & 0,704 & 1 \\
G & 0,840 & 1 & 0,780 & 1 & 0,513 & 3 & 0,704 & 2 \\
N & 0,302 & 6 & 0,464 & 3 & 0,489 & 4 & 0,415 & 3 \\
J & 0,320 & 5 & 0,250 & 7 & 0,578 & 1 & 0,373 & 4 \\
B & 0,464 & 3 & 0,267 & 6 & 0,338 & 6 & 0,354 & 5 \\
D & 0,296 & 7 & 0,333 & 5 & 0,338 & 5 & 0,322 & 6 \\
F & 0,173 & 10 & 0,340 & 4 & 0,320 & 7 & 0,273 & 7 \\
E & 0,356 & 4 & 0,187 & 9 & 0,160 & 11 & 0,228 & 8 \\
I & 0,200 & 9 & 0,200 & 8 & 0,202 & 10 & 0,201 & 9 \\
K & 0,122 & 11 & 0,187 & 10 & 0,250 & 8 & 0,183 & 10 \\
\hline
\end{tabular}

As respostas a respeito das causas de aumentos dos custos também foram hierarquizadas tomando como parâmetro o FI. As cinco causas mais frequentes na opinião geral dos entrevistados foram apresentadas na Tabela 11, sendo, em ordem decrescente:

(a) "levantamento de quantitativos de serviços subestimados na planilha";

(b) "serviços não previstos no orçamento ou ausência de itens na planilha";

(c) "falhas em projetos ou projetistas inexperientes";

(d) "falhas na gestão do tempo"; e

(e) "condições do subsolo inesperadas".

Entre as cinco primeiras causas dos rankings de RII e de FI quatro são comuns, significando que importantes causas de aditivos de valor também estão entre as que mais se repetem e, consequentemente, geram consideráveis acréscimos nos custos das obras. Esses resultados são mais bem expressados pelos valores dos IMPI, apresentados na Tabela 12.

Conforme a Tabela 12, as principais causas de acréscimos de custos nas obras da autarquia foram, em ordem decrescente do IMPI: "levantamento de quantitativos de serviços subestimados na planilha" e "serviços não previstos no orçamento ou ausência de itens na planilha", seguidos de "falhas em projetos ou projetistas inexperientes", "falhas na gestão do tempo" e "condições do subsolo inesperadas". O IMPI das duas principais causas dos aditivos de valores são consideravelmente maiores que o IMPI das demais, o que sugere a relevância dos aditivos motivados por essas causas. Esses dados corroboram Arditi, Akan e Gurdamar (1985), que afirmam que as deficiências nas estimativas de custos elaboradas pelos órgãos públicos implicam custos adicionais. As três primeiras causas do ranking de IMPI estão diretamente relacionadas aos projetistas, e a quarta causa nesse ranking ("falhas na gestão do tempo") é oriunda principalmente da má atuação nos projetos, como foi mostrado anteriormente. Portanto, a atuação dos projetistas afeta consideravelmente os acréscimos nos custos das obras.

Em termos das causas dos acréscimos nos custos das obras, a maior concordância das respostas ocorreu entre os grupos dos "supervisores de obras" e o dos "engenheiros das obras", com coeficiente de correlação de Spearman de 0,907. Os grupos de "supervisores de projetos" e "supervisores de obra" apresentaram valor de 0,836 para o coeficiente de Spearman, enquanto os de "supervisores de projetos" e "engenheiros das obras" o valor de 0,828. Como discutido anteriormente, números acima de 0,7 são considerados como de alta concordância para as respostas.

\section{Conclusões}

A quantidade de obras da autarquia afetadas com aditivos contratuais de prazo e valor, assim como a intensidade desses aditivos, deixa clara a existência de um grave problema que afeta o uso dos recursos públicos. Embora o desenvolvimento do trabalho tenha sido realizado com base na análise das obras de uma autarquia municipal, o referencial teórico avaliado demonstra que outras entidades públicas possuem problemas semelhantes.

Ainda que eventuais diferenças de entendimento do problema não sejam por si conclusivas, sugerese a possibilidade de que a percepção dos agentes envolvidos esteja associada a um modelo tradicional de gestão de empreendimentos públicos, potencializado pela falta de integração entre as fases de projeto e produção, causada em parte pelos mecanismos de contratação impostos 
pela Lei das Licitações. No planejamento e execução dos empreendimentos não são consideradas as interdependências entre atividades, nem são considerados no início do projeto potenciais riscos. Se o atual mecanismo de contratação exige que o projeto e a execução sejam separados, os agentes públicos contratantes e as empreiteiras contratadas deveriam fazer uma análise crítica dos projetos.

Associada a isso está a questão da definição de novas responsabilidades para os agentes públicos responsáveis pela fiscalização dos contratos, responsabilidades essas que também devem compreender a efetiva gestão dos contratos, ou seja, o monitoramento dos serviços contratados, de forma a serem atendidas as metas de desempenho no custo e prazo acordados. Com frequência, a preocupação principal é com o atendimento a requisitos legais dos processos licitatórios, porém pouca atenção é dada à avaliação, à análise crítica dos projetos ou aos planos de gerenciamento do empreendimento do ponto de vista da gestão do processo de projeto. Neste contexto, entende-se por gestão do processo de projeto a utilização de modelos para a definição do escopo, desenvolvimento dos programas de necessidades dos empreendimentos, coordenação de interfaces entre as disciplinas de projeto, bem como o controle de custos, prazos e qualidade dos produtos (projetos) desenvolvidos ao longo de fases previamente definidas. Da mesma forma, pouca atenção é dada pelo contratante à análise do sistema ou às ferramentas de planejamento $\mathrm{e}$ controle da produção. Esse fato, associado a uma visão reducionista da responsabilidade dos contratantes, também foi observado na literatura recente.

As análises promovidas dos fatores Índice de Importância Relativa (RII), Índice de Frequência (FI) e Índice de Importância (IMPI) sugerem que as principais causas dos aumentos nos prazos de entrega dos empreendimentos estão associadas a problemas na fase de concepção e de projeto dos empreendimentos, como falhas na compatibilização dos projetos ou questões decorrentes de deficiências nos desdobramentos da etapa de projetos, como é o caso da orçamentação e planejamento da produção. Portanto, são questões anteriores às fases de obra (de canteiro) e de atuação dos empreiteiros.

Por outro lado, as várias causas de aditivos oriundas do processo de projeto e que só são detectadas na fase de obra apontam para a necessidade de implementação de mecanismos que privilegiem o desenvolvimento integrado dos empreendimentos, integrando projeto e execução. Nesse sentido, o órgão público poderia estabelecer diretrizes para que as fases de projeto e execução fossem integradas a partir da introdução no projeto de requisitos de construtibilidade e racionalização da produção, requisitos esses que podem ser estabelecidos sem implicar o possível favorecimento de futuros participantes nas licitações.

Também se tornam necessárias modificações na forma como os projetos para obras públicas são apresentados; por exemplo, através da inserção no "Termo de Referência de Contratação de Projetos" de requisitos que incluem a antecipação de atividades que tradicionalmente são realizadas durante a obra, mas que poderiam ser feitas na fase de projeto. A promoção de alterações no fluxo tradicional de desenvolvimento e apresentação dos projetos (de forma a atender às particularidades dos órgãos públicos devido à Lei de Licitações) e o desenvolvimento de modelos práticos de listas de verificações também seriam fatores importantes para melhorias na coordenação dos projetos. Esses aspectos estão alinhados com algumas recomendações da literatura, indicadas anteriormente, que sugerem melhorias nos documentos associados à licitação (como especificações técnicas, desenhos e planilhas de quantitativos) e à implementação de mecanismos para se garantir a elaboração do projeto com qualidade.

$\mathrm{Na}$ situação ideal, os mecanismos de licitação deveriam romper com a lógica da contratação pelo menor preço, o que pode resultar na possibilidade de que empresas sem qualificação ou compromisso com as metas de desempenho do empreendimento forneçam soluções de projeto que comprometam as obras públicas.

$\mathrm{Na}$ mesma linha de raciocínio, a lógica das contratações públicas deve ser repensada em termos das relações entre contratantes e empresas contratadas, muitas vezes pautadas no princípio de aproveitar situações de litígio para obter vantagens, que, em alguns casos, podem até ser eticamente legítimas. Nesse sentido, os mecanismos de contratação associados à gestão de pleitos devem ser reconsiderados, podendo ser objeto de pesquisas futuras.

Com embasamento nos pontos destacados, esperase que o aprimoramento da gestão do processo de projeto, associado a uma maior coerência em se estabelecerem os prazos das obras, além do melhoramento dos processos de composição de itens extras e revisões de projetos, possa contribuir para uma potencial redução de aditamentos contratuais de valor e prazo em edificações públicas, com a consequente melhoria da 
qualidade das obras e melhor uso dos recursos públicos.

\section{Referências}

AIBINU, A. A.; JAGBORO, G. O. The Effects of Construction Delays on Project Delivery in Nigerian Construction Industry. International Journal of Project Management, v. 20, n. 8, p. 593-599, 2002.

ALAGHBARI, W.; KADIR, M. R. A.; ERNAWATI, A. S. The Significant Factors Causing Delay of Building Construction Projects in Malaysia. Engineering, Construction and Architectural Management, v. 14, n. 2, p. 192206, 2007.

AL-MOMANI, A. H. Construction Delay: a quantitative analysis. International Journal of Project Management, v. 18, n. 1, p. 51-59, 2000.

ARDITI, D.; AKAN G. T.; GURDAMAR S. Cost Overruns in Public Projects. Projetct

Management, v. 3, n. 4, p. 218-224, 1985.

ASSAF, S. A.; AL-HEJJI S. Causes of Delay in Large Construction Projects. International Journal of Project Management, v. 24, n. 4, p. 349-357, 2006.

BRASIL. Decreto-lei no 8.666, de 21 de junho de 1993, que institui normas para licitações e contratos da Administração Pública e dá outras providências. Diário Oficial do Estado de São Paulo, São Paulo, 22 de junho de 1993.

BRASILIANO, A. E.; CALMON, J. L. Um Modelo de Gestão do Desenvolvimento de Projetos das Edificações Públicas Baseado nos Princípios da Engenharia Simultânea. In SEMINÁRIO SOBRE LEAN CONSTRUCTION, 5.; SEMINÁRIO INTERNACIONAL SOBRE LEAN DESIGN BUILD, São Paulo, 2000. Anais... São Paulo, 2000.

BRETAS, E. S. O Processo de Projetos de Edificações em Instituições Públicas: proposta de um modelo simplificado de coordenação. Belo Horizonte, 2010. 134 f. Dissertação (Mestrado em Construção Civil) - Escola de Engenharia, Universidade Federal de Minas Gerais, Belo Horizonte, 2010.

CANONICO, M. R. S. O. Proposta de Processo Para a Elaboração da Fase Interna da Licitação na Contratação de Obras de construção civil pelo setor público. Curitiba, 2011. $147 \mathrm{f}$. Dissertação (Mestrado em Engenharia Civil) Programa de Pós-Graduação em Engenharia Civil, Universidade Tecnológica Federal do Paraná, Curitiba, 2011.
CHENG, Y. M. An Exploration Into CostInfluencing Factors on Construction Projects. International Journal of Project Management, v. 32, n. 5, p. 850-860, 2014.

CREEDY, G. Risk Factors Leading to Cost Overrun in Highway Construction Projects. In: INTERNATIONAL SYMPOSIUM ON CLIENT DRIVING INNOVATION, 2., Brisbane, 2004. Anais... Brisbane, 2004.

DESAI, M.; BHATT, R. Critical Causes of Delay in Residential Construction Projects: case study of Central Gujarat Region of India. International Journal of Engineering Trends and Technology, v. 4, p. 762-768, 2013.

DOLOI, H. et al. Analysing Factors Affecting Delays in Indian Construction Projects. International Journal of Project Management, v. 30, n. 4, p. 479-489, 2012.

EL-RAZEK, M. E. A.; BASSIONI, H. A.; MOBARAK A. M. Causes of Delay in Building Construction Projects in Egypt. Journal of Construction Engineering and Management, v. 134, n. 11, p. 831-841, 2008.

ENSHASSI, A.; AL-NAJJAR, J.;

KUMARASWAMY M. Delays and Cost Overruns in the Construction Projects in the Gaza Strip. Journal of Financial Management of Property and Construction, v. 14 n. 2, p. 126-151, 2009.

FLYVBJERG, B.; HOLM, M.; BUHL, S. What Causes Cost Overrun in Transport Infrastructure Projects? Transport Reviews, v. 2, n. 1, p. 3-18, jan. 2004.

GIL, A. C. Métodos e Técnicas de Pesquisa Social. 2. ed. São Paulo: Atlas, 1989.

GOMES, R. C. G. A Postura das Empresas Construtoras de Obras Públicas da Grande Florianópolis em Relação ao PBQP-H. Florianópolis, 2007. 173 f. Dissertação (Mestrado em Engenharia Civil) - Escola de Engenharia, Universidade Federal de Santa Catarina, Florianópolis, 2007.

GUNDUZ, M.; NIELSEN, Y.; OZDEMIR, M. Fuzzy Assessment Model to Estimate the Probability of Delay in Turkish Construction Projects. Journal of Management in Engineering, v. 31, n. 4, p. 1-14, 2015.

HSIEH, T.; LU, S.; WU, C. Statistical Analysis of Causes For Change Orders in Metropolitan Public Works. International Journal of Project Management, v. 22, n. 8, p. 679-686, 2004. 
IYER, K. C.; CHAPHALKAR, N. B.; JOSHI, G. A. Understanding Time Delay Disputes in Construction Contracts. International Journal of Project Management, v. 26, n. 2, p. 174-184, 2008.

KHALED, A.; KARTAM, N. Design-Build Pre Qualification and Tendering Approach For Public Projetcs. International Journal of Project Management, v. 23 n. 4, p. 309-320, 2005.

LO, T. Y.; FUNG, I. W. H.; TUNG, K. C. F. Construction Delays in Hong Kong Civil Engineering Projects. Journal of Construction Engineering and Management, v. 132, n. 6, p. 636-649, 2006.

LOVE, P. et al. Rework in Civil Infrastructure Projects: determination of cost predictors. Journal of Engineering Construction and Management. v. 136, n. 3, p. 275-282, 2010.

MARZOUK, M. M.; EL-RASAS, T. I. Analyzing Delay Causes in Egyptian Construction Projects. Journal of Advanced Research, v. 5, n. 1, p. 49$55,2014$.

MAYR, L. R.; VARVAKIS, G. Ruídos no Processo de Comunicação: o caso de obras públicas realizadas para a UFSC. In: SEMINÁRIO DE TECNOLOGIA DA INFORMAÇÃO E COMUNICAÇÃO NA CONSTRUÇÃO CIVIL, 2., São Paulo, 2005. Anais... São Paulo, 2005.

MCGRAW HILL CONSTRUCTION. Managing Uncertainty and Expectations in Building Design and Construction. Smart Market Report. 2014.

ODEH, A. M.; BATTAINEH, H. T. Causes of Construction Delay: traditional contracts. International Journal of Project Management, v. 5, n. 1, p. 67-73, 2002.

OLIVEIRA, J. O.; MELHADO, S. B. O Papel do Projeto em Empreendimentos Públicos: dificuldades e possibilidades em relação à qualidade. In: WORKSHOP NACIONAL GESTÃO DO PROCESSO DE PROJETO NA CONSTRUÇÃO DE EDIFÍCIOS, Porto Alegre, 2002. Anais... Porto Alegre, 2002.

PEREIRA, E. S. S. Fatores Associados ao Atraso na Entrega de Edifícios Residenciais. Florianópolis, 2012. 204 f. Dissertação (Mestrado em Construção Civil) - Escola de Engenharia, Universidade Federal de Santa Catarina, Florianópolis, 2012.

PEREIRA, E. et al. Causas do Atraso na Entrega de Edifícios Residenciais. In: ENCUENTRO LATINO-AMERICANO DE GESTIÓN Y ECONOMÍA DE LA CONSTRUCCIÓN, 4., Santiago, 2011. Anais... Santiago, 2011.
PEREZ, C. Proposta e Implementação de Um Plano de Qualidade Para Obras Públicas de Pequeno Porte. Belo Horizonte, 2011. 182 f. Dissertação (Mestrado em Construção Civil) Escola de Engenharia, Universidade Federal de Minas Gerais, Belo Horizonte, 2011.

PROYER, M.; GRIMSCHEID, G. Requirement Engineering and the Effect on Cost Compliance in the Holistic, Life Cycle Oriented Yield, Cost Planning and Controlling Process. In: SIMPÓSIO BRASILEIRO DE GESTÃO E ECONOMIA DA CONSTRUÇÃO, 8., Salvador, 2013. Anais... Salvador, 2013.

RAMABODU, M.; VESTER, P. Factors Contributing to Cost Overruns of Construction Projects. In: INTERNATIONAL SYMPOSIUM BUILT ENVIRONMENT CONFERENCE, 5., Durban, 2010. Anais... Durban: CIB, 2010.

RODRIGUES, C. Contribuição à Gestão de Contratos Para Reforma de Imóveis Usados Pela Administração Pública. 2010. 206 f. Dissertação (Mestrado em Construção Civil) Escola de Engenharia, Universidade Federal de Minas Gerais, Belo Horizonte, 2010.

ROOKE, J.; SEYMOUR, D.; FELLOWS, R. Planning for Claims: an ethnography of industry culture. Construction Management and Economics, v. 22, n. 6, p. 655-682, 2004.

SAMBASIVAN, M.; SOON, Y. W. Causes and Effects of Delays in Malaysian Construction Industry. International Journal of Project Management, v. 25, n. 5, p. 517-526, 2007.

SANTOS, A. et al. Crítica ao Processo de Contratação de Obras Públicas no Brasil. In: ENCONTRO NACIONAL DE TECNOLOGIA DO AMBIENTE CONSTRUÍDO, 14., Foz do Iguaçu, 2002. Anais... Foz do Iguaçu: ANTAC, 2002.

SANTOS, H. P. Diagnóstico e Enálise das Causas de Aditivos Contratuais de Prazo e Valor em Obras de Edificações em Uma Instituição Pública. Belo Horizonte, 2015. $171 \mathrm{f}$. Dissertação (Mestrado em Construção Civil) Escola de Engenharia, Universidade Federal de Minas Gerais, Belo Horizonte, 2015.

SHEHU, Z. et al. Cost overrun in the Malaysian construction industry projects: a deeper insight. International Journal of Project Management, v. 32, n. 8, p. 1471-1480, 2014.

SHELBOURN, M. et al. Collaboration: key concepts. In: BOUCHLAGHEM, D (Ed.). Collaborative Working in Constrution. London: Spoon Press, 2012. 
SILVA, M. E. M. Diretrizes Para Gestão de Projetos de Obras Públicas: o caso da UFPA. Belém, 2011. 120 f. Dissertação (Mestrado em Engenharia Civil) - Instituto de Tecnologia da Universidade Federal do Pará, Belém, 2011.
TAWIL, N. M. et al. Factors Contribute to Delay Project Construction in Higher Learning Education Case Study UKM. Research Journal of Applied Sciences, Engineering and Technology, v. 5, n. 11, p. 3112-3116, 2013.

Henrique de Paula Santos

Departamento de Engenharia de Materiais e Construção Civil, Escola de Engenharia | Universidade Federal de Minas Gerais | Av. Antônio Carlos, 6627, Sala 3401, Bloco 1 do Prédio da Escola de Engenharia, Pampulha | Belo Horizonte - MG - Brasil | CEP $31270-901$ |

Tel.: (31) 3409-1850 | E-mail: henriquedepaulasantos@gmail.com

\section{Cícero Murta Diniz Starling}

Departamento de Engenharia de Materiais e Construção Civil, Escola de Engenharia | Universidade Federal de Minas Gerais | Sala 3312 | Tel.: (31) 3409-1858 | E-mail: cicerostarling@ufmg.br

\section{Paulo Roberto Pereira Andery}

Departamento de Engenharia de Materiais e Construção Civil, Escola de Engenharia | Universidade Federal de Minas Gerais | Av. Presidente Antônio Carlos, 6627, Bloco I, Sala 3314, São José | Belo Horizonte - MG - Brasil | CEP 31275-013 | Tel.: (31) 3409-1856 | E-mail: pandery@ufmg.br

\section{Revista Ambiente Construído}

Associação Nacional de Tecnologia do Ambiente Construído

Av. Osvaldo Aranha, $99-3^{\circ}$ andar, Centro

Porto Alegre - RS - Brasil

$$
\text { CEP } 90035-190
$$

Telefone: +55 (51) 3308-4084

Fax: +55 (51) 3308-4054

www.seer.ufrgs.br/ambienteconstruido

E-mail: ambienteconstruido@ufrgs.br 